\title{
Impaired associative fear learning in mice with complete loss or haploinsufficiency of AMPA GluR1 receptors
}

\author{
Michael Feyder ${ }^{1}$, Lisa Wiedholz ${ }^{1}$, Rolf Sprengel ${ }^{2}$ and Andrew Holmes ${ }^{1 *}$ \\ 1. Section on Behavioral Science and Genetics, Laboratory for Integrative Neuroscience, National Institute on Alcohol Abuse and Alcoholism, \\ National Institutes of Health, USA \\ 2. Max-Planck Institute for Medical Research, Germany
}

Edited by: Carmen Sandi, Ecole Polytechnique Federale De Lausanne, Switzerland

Reviewed by: Sabrina Davis, Université Paris Sud, France

Lisa A. Conboy, Ecole Polytechnique Fédérale de Lausanne, Switzerland

There is compelling evidence that L-alpha-amino-3-hydroxy-5-methylisoxazole-4-propionate (AMPA) glutamate receptors containing the GluR1 subunit contribute to the molecular mechanisms associated with learning. AMPA GluR1 glutamate receptor knockout mice (KO) exhibit abnormal hippocampal and amygdala plasticity, and deficits on various assays for cognition including Pavlovian fear conditioning. Here we examined associative fear learning in mice with complete absence (KO) or partial loss (heterozygous mutant, HET) of GluR1 on multiple fear conditioning paradigms. After multi-trial delay or trace conditioning, KO displayed impaired tone and context fear recall relative to WT, whereas HET were normal. After one-trial delay conditioning, both KO and HET showed impaired tone and context recall. HET and KO showed normal nociceptive sensitivity in the hot plate and tail flick tests. These data demonstrate that the complete absence of GluR1 subunit-containing receptors prevents the formation of associative fear memories, while GluR1 haploinsufficiency is sufficient to impair one-trial fear learning. These findings support growing evidence of a major role for GluR1-containing AMPA receptors in amygdalamediated forms of learning and memory.

Keywords: glutamate, learning, GluR1, AMPA, mouse

\section{INTRODUCTION}

L-Alpha-amino-3-hydroxy-5-methylisoxazole-4-propionate (AMPA) receptors are postsynaptic hetero-oligomeric proteins composed of one or more glutamate receptor GluR1-GluR4 subunits (Shi et al., 2001). There is compelling evidence that AMPA receptors containing the GluR1 subunit play a critical role in the mediation of synaptic plasticity (Collingridge et al., 2004; Lledo et al., 1998; Malinow and Malenka, 2002). There are currently no pharmacological compounds to probe the specific function of individual AMPA receptor subunits. However, studies with GluR1 knockout mice (KO) demonstrate impairments in certain forms of synaptic plasticity, including long-term potentiation, a putative molecular mechanism for learning (Hoffman et al., 2002; Mack et al., 2001; Zamanillo et al., 1999), and deficits in learning and memory performance on a range of behavioral tasks (Johnson et al., 2005; Mead et al., 2005;

\footnotetext{
* Correspondence: Andrew Holmes, Section on Behavioral Science and Genetics, Laboratory for Integrative Neuroscience, National Institute on Alcohol Abuse and Alcoholism, National Institutes of Health, 5625 Fishers Lane, Room 2N09, Rockville MD 20852-9411, USA. e-mail: holmesan@mail.nih.gov

Received: 13 Oct. 2007; paper pending published: 16 Nov. 2007; accepted: 12 Dec. 2007; Published online: 30 Dec. 2007

Full citation: Frontiers in Behavioral Neuroscience (2007) 1:4 doi: 10.3389/neuro.08/ 004.2007

Copyright (C) 2007 Feyder, Wiedholz, Sprengel and Holmes. This is an open-access article subject to an exclusive license agreement between the authors and the Frontiers Research Foundation, which permits unrestricted use, distribution, and reproduction in any medium, provided the original authors and source are credited.
}

Mead and Stephens, 2003; Reisel et al., 2002; Schmitt et al., 2003; Schmitt et al., 2004a; Schmitt et al., 2004b; Schmitt et al., 2005; Zamanillo et al., 1999).

Pavlovian fear conditioning is a commonly used paradigm for assessing associative learning and memory in rodents (Fanselow and Poulos, 2005; LeDoux, 2000). GluR1-containing AMPA receptors are highly expressed in rodent brain regions mediating fear learning including the amygdala and hippocampus (McDonald, 1996; Zamanillo et al., 1999). There is strong evidence of a critical role for GluR1-containing AMPA receptors in the formation of fear memories using the Pavlovian conditioning paradigm (Hu et al., 2007; Rumpel et al., 2005; Yeh et al., 2006). Recently, Humeau and colleagues reported that GluR1 KO exhibited impairments in LTP in the basolateral amygdala and deficient fear conditioning using a multi-trial tone-shock protocol (Humeau et al., 2007).

In the present study, we sought to extend these findings by comparing mice completely lacking GluR1 (KO) and mice with GluR1 haploinsufficiency (heterozygous, HET) on various forms of fear conditioning. In addition to a standard multi-trial delay conditioning paradigm (Kim and Fanselow, 1992), a one-trial paradigm was employed based on evidence that pharmacologic and genetic inactivation of glutamate receptors can preferentially impair learning following one-trial leaning (Bast et al., 2005; Bonini et al., 2003; Cravens et al., 2006; Day et al., 2003; De Leonibus et al., 2003; Dere et al., 2007; Nakazawa et al., 2003). Trace fear conditioning was also tested. This is a hippocampal-mediated form of associative fear learning (Kim et al., 1995; Misane et al., 2005) sensitive to glutamate receptor inactivation (Huerta et al., 2000; Wanisch et al., 2005). Previous work has shown that GluR1 KO mice are impaired on hippocampal-mediated tasks, such as spatial learning in the T-maze (for review, see (Bannerman et al., 2006). 


\section{MATERIALS AND METHODS Subjects}

GluR1 mutant mice were generated as previously described (Zamanillo et al., 1999). For the present behavioral study, GluR1 K0, HET, and WT mice ( 75\% C57BL/6J) were littermates bred from HET $\times$ HET parents at The Jackson Laboratory (Bar Harbor, ME) and transported to $\mathrm{NIH}$ at $\sim 8$ weeks of age in littermate groupings (Weidholz et al., 2007). Mice were housed in same-sex littermate groupings in a temperature- and humidity-controlled vivarium under a 12 hours light/dark cycle (lights on 0600 hours) and given 2-week acclimation before testing. Testing was conducted during the light phase between 0900 and 1700 . Separate cohorts of mice were tested for multi-trial and one-trial delay conditioning and multi-trial trace conditioning. Hot plate and tail flick testing was conducted in a subset of mice. Males and females were used. The number of animals tested is given in the figure legends. All experimental procedures were performed in accordance with the National Institutes of Health Guide for Care and Use of Laboratory Animals and were approved by the local Animal Care and Use Committee.

\section{Pavlovian fear conditioning}

Multi-trial delay fear conditioning. Multi-trial delay fear conditioning was conducted as previously described (Hefner and Holmes, 2007; Kim and Fanselow, 1992). The apparatus was a $27 \times 27 \times 11 \mathrm{~cm}^{3}$ chamber with transparent walls and a metal rod floor. The chamber was cleaned between subjects with a $79.5 \%$ water $/ 19.5 \%$ ethanol $/ 1 \%$ vanilla extract solution. After an initial 120 seconds acclimation period, the mouse received four pairings (60-120 seconds interval after each pairing) between a 30 seconds, $80 \mathrm{~dB}, 3 \mathrm{kHz}$ tone and a 2 seconds, $0.6 \mathrm{~mA}$ scrambled footshock, in which the tone was presented during the last 2 seconds of the shock. The presentation of stimuli was controlled by the San Diego Instruments Freeze Monitor system (San Diego Instruments, San Diego, CA). Twenty-four hours later, tone recall was tested in a different room from training in a novel chamber with black/whitecheckered walls and a solid-Plexiglas, opaque floor cleaned between subjects with a $50 \%$ ethanol $/ 50 \%$ water solution. After a 180 seconds acclimation period, the tone was continuously presented for 180 seconds. Twenty-four hours later, context recall was tested by returning the mouse to the training chamber for 5 minutes. Freezing during recall was defined as the absence of any visible movement except that required for respiration, and scored at 5 seconds intervals by an observer blind to genotype. The number of observations scored as freezing were converted to a percentage ([number of freezing observations/total number of observations] $\times 100$ ) for the analysis.

Multi-trial trace fear conditioning. Multi-trial trace fear conditioning was conducted using the same procedure as used for multi-trial delay fear conditioning, with the exception that there was a 15 seconds "trace" interval between cessation of the tone and the onset of the shock. Trace conditioning using this interval is disrupted by hippocampus lesions in C57BL/6J mice (Misane et al., 2005).

One-trial delay fear conditioning. One-trial delay fear conditioning was conducted using the same procedure as for the multi-trial delay paradigm with the exception that there was only one tone-shock pairing and the shock intensity was increased slightly to $0.8 \mathrm{~mA}$.

\section{Nociception}

Given an earlier finding that GluR1 KO mice exhibit reduced acute inflammatory hyperalgesia and abnormal nociceptive plasticity in vitro (Hartmann et al., 2004), the hot plate and tail flick assays were used to test for nociception in vivo (Boyce-Rustay and Holmes, 2006). The hot plate (Columbus Instruments, Columbus, $\mathrm{OH}$ ) was heated to $55^{\circ} \mathrm{C}$, and the latency to show a hind paw shake or lick was timed by an observer, with a maximum response latency of 30 seconds to prevent possible tissue damage. For the tail flick test, the mouse was placed in a restrainer with the tail exposed to an intense light beam (Columbus Instruments tail flick monitor, Columbus, $\mathrm{OH}$ ). The latency to show a tail flick reflex was recorded automatically by a photobeam monitor, with a maximum response latency of 10 seconds to prevent possible tissue damage.

\section{Statistics}

The effect of genotype on conditioned freezing, and hot plate and tail flick response scores were analyzed using analysis of variance followed by Newman-Keuls post-hoc tests. Statistical significance was set at $p<0.05$.

\section{RESULTS}

\section{Multi-trial delay fear conditioning}

Following multi-trial delay fear conditioning, there was significant effect of genotype for freezing during tone recall $(F 2,42=74.60, p<0.01)$ and during context recall $(F 2,42=23.19, \quad p<0.01)$. Newman-Keuls post-hoc tests showed that KO but not HET showed significantly less than WT during tone (Figure 1A) and context (Figure 1B) recall.

\section{Multi-trial trace fear conditioning}

Following multi-trial trace fear conditioning, there was significant effect of genotype for freezing during tone recall $(F 2,21=6.76, p<0.01)$. Post-hoc tests showed that KO but not HET showed significantly less than WT during tone (Figure 1C).

\section{One-trial delay fear conditioning}

Following one-trial delay fear conditioning, there was significant effect of genotype for freezing during tone recall $(F 2,33=24.79, p<0.01)$ and during context recall $(F 2,33=9.66, p<0.01$; Figure $2 \mathrm{~B})$. Post-hoc tests showed that $\mathrm{KO}$ and HET showed significantly less than WT during tone (Figure 2A) and context (Figure 2B) recall.

\section{Nociception}

GluR1 K0 and GluR1 HET mice showed normal nociceptive responses in the hot plate test (WT $=11.5 \pm 0.9$ seconds to respond, HET $=$ $12.5 \pm 1.2, \quad \mathrm{~K} 0=9.7 \pm 0.9) \quad$ and tail flick test (WT $=2.0 \pm$ 0.1 seconds to respond, $\mathrm{HET}=2.2 \pm 0.2, \mathrm{KO}=1.8 \pm 0.1$ ).

\section{DISCUSSION}

The principle finding of the present study was impaired Pavlovian fear conditioning in mice completely lacking or deficient in the AMPA GluR1 subunit across a range of protocols. Humeau and colleagues (Humeau et al., 2007) recently reported impaired fear conditioning in GluR1 K0 using a protocol comparable to the multi-trial delay protocol used in the current study, in which mice received multiple concomitant tone-shock pairings. In both studies, GluR1 K0 exhibited less conditioned freezing to tone and context than WT controls. Although GluR1 KO show reduced acute inflammatory hyperalgesia (Hartmann et al., 2004), fear learning deficits in the $\mathrm{KO}$ mice were not explained by a loss of sensitivity to pain, as demonstrated by normal nociceptive responses in the hot plate and tail flick assays and by the observation that $\mathrm{KO}$ exhibited jumping and vocalizing during footshock. It is also unlikely that reduced fear behavior was caused by abnormally low levels of anxiety-like behavior, as GluR1 $\mathrm{KO}$ has been found to show modest increases in these behaviors on certain tests (Bannerman et al., 2004). Rather, impaired fear conditioning is consistent with previous studies showing cognitive and executive deficits in GluR1 KO on a variety of tests taxing processes ranging from spatial working memory and reversal to control over drug seeking (for reviews, see (Bannerman et al., 2006; Stephens and Mead, 2003)).

Current models posit that the lateral nucleus of the amygdala serves as a convergence site for sensory and aversive information that is relayed either directly or via the basal nucleus to the major output center of the amygdala, the central nucleus, to drive conditioned fear behaviors (Fanselow and LeDoux, 1999; Maren and Quirk, 2004). Humeau et al., 
A

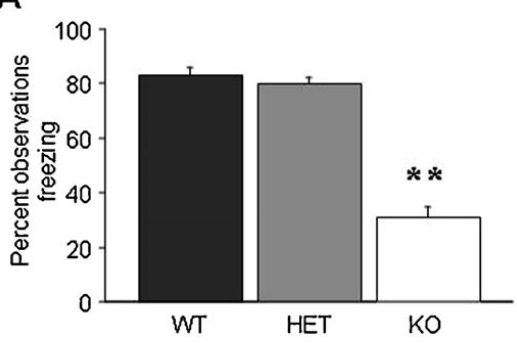

B

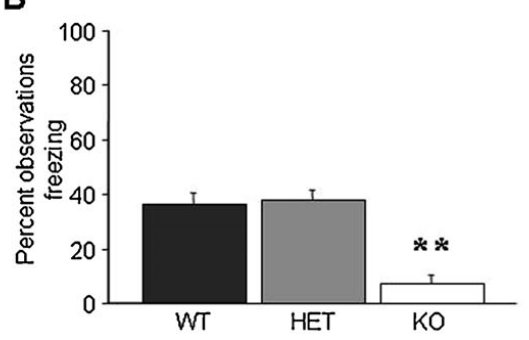

C

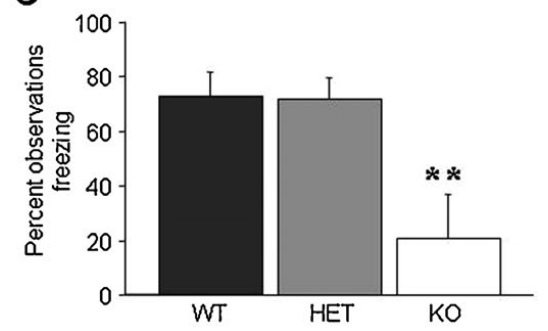

Figure 1. GluR1 KO but not HET exhibit impaired multi-trial delay and trace fear conditioning. (A) KO showed less freezing than WT during tone recall in the multi-trial delay fear conditioning paradigm. (B) KO showed less freezing than WT during context recall in the multi-trial trace fear conditioning paradigm ( $n=15$ / genotype). (C) KO showed less freezing than WT during tone recall in the multi-trial trace fear conditioning paradigm ( $n=6-12 / g e n o t y p e)$. Data are means $\pm S E M$. ${ }^{* *} p<0.01$ versus $W T$.

found markedly impaired thalamo-amygdala and cortico-amygdala LTP in GluR1 K0. This is consistent with earlier work showing that fear conditioning in the rat led to incorporation of GluR1-containing subunits in thalamo-amygdala synapses and that blockade of this process via infection of neurons with a GluR1-blocking viral vector prevented fear memory formation (Rumpel et al., 2005; Yeh et al., 2006). Extending these findings, very recent data show that GluR1 phosphorylation also mediates the ability of norepinephrine to promote fear memory (Hu et al., 2007). Taken together, abnormal amygdala plasticity provides a plausible physiological candidate for the fear conditioning deficits observed in GluR1 K0.

GluR1 K0 were impaired on a (multi-trial) trace fear conditioning paradigm that is sensitive to hippocampal inactivation in mice (Misane et al., 2005). GluR1 K0 mice are impaired on hippocampus-dependent tasks such as T-maze spatial learning (Bannerman et al., 2006). Because KO of GluR1 impairs both trace conditioning and delay conditioning, and both forms of conditioning are amygdala-mediated (Fanselow and Poulos, 2005; LeDoux, 2000), the trace fear deficit is most parsimoniously explained as further evidence of abnormal amygdala function in these mice. However, the contribution of a hippocampal deficit to the trace conditioning impairment in these mice cannot be excluded and would in fact be congruent with previously observed GluR1 KO impairments in hippocampal synaptic plasticity and hippocampal-mediated forms of learning such as spatial working and reference memory (Mack et al., 2001; Schmitt et al., 2005; Zamanillo et al., 1999).

Present data predict that loss of GluR1 function in amygdala neurons would cause deficits in other cognitive tasks mediated by this brain region. Interestingly in this context, Johnson and colleagues (Johnson et al., 2005) reported that GluR1 K0 failed to show reinforcer devaluation, a phenomenon in which operant responding for a food reward is reduced by sating the animal's desire for the reward prior to testing (Balleine and Dickinson, 1998). Reinforcer devaluation is impaired by basolateral nucleus of the amygdala (BLA) lesions in rats (Hatfield et al., 1996). Previous studies have also shown that GluR1 KO demonstrate intact instrumental responding for reward, but are significantly slower to learn to respond to a cue predictive of primary reward (Mead and Stephens, 2003). Again, these behaviors are disrupted by lesions of the BLA (Everitt et al., 2000) and by BLA-administration of the AMPA receptor antagonist CNQX (Hitchcott and Phillips, 1997). Taken together, these findings provide converging evidence of impairments in GluR1 $\mathrm{KO}$ across multiple forms of amygdala-mediated learning. Further studies will be required, however, to test fear conditioning in these mice under other conditions. For example, it would be important to test whether the GluR1 K0 deficit can be rescued by overtraining (e.g., numerous or high shock conditioning trials), as has been shown for other mutant fear conditioning deficits (e.g., (Bozon et al., 2003; Jones et al., 2001; Kogan et al., 1997)).

An important finding was that GluR1 HET mice with GluR1 haploinsufficiency exhibited normal (WT levels) of tone and context fear in both the multi-trial delay and trace fear conditioning paradigms, but were significantly impaired on a one-trial delay fear conditioning paradigm. The deficit was evident for both tone and context conditioning, but lesser than that exhibited in GluR1 K0 -indicative of a gene-dosagedependent phenotype. Thus, while complete loss of GluR1 severely disrupts the formation of associative fear memories, partial loss of GluR1 appears to produce a more subtle fear-learning deficit that manifest after a single learning event but which can be overcome when multiple learning opportunities are available. Although the molecular underpinnings of such a one-trial versus multi-trial dissociation are not clear, the relative lack of a GluR1 in HET mice could be insufficient to permit the necessary rapid synaptic incorporation of GluR1 during a one-trial learning event.
A

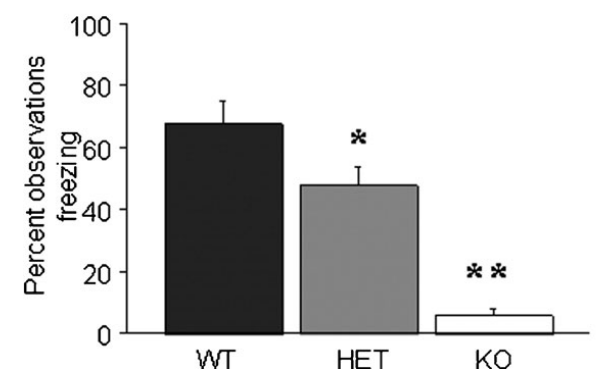

B

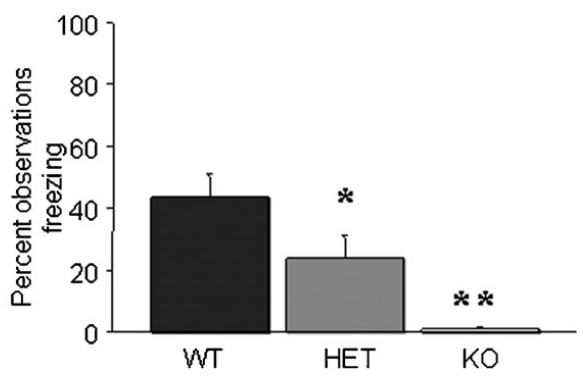

Figure 2. GluR1 KO and HET exhibit impaired one-trial delay fear conditioning. (A) KO and HET showed less freezing than WT during tone recall. (B) KO and HET showed less freezing than WT during context recall. $n=10-13 /$ genotype. Data are means $\pm S E M .{ }^{* *} p<0.01,{ }^{*} p<0.05$ versus WT. 
GluR1 KO rather than HET have been the focus of most studies in this mutant line (Bannerman et al., 2006; Sprengel, 2006) and to our knowledge, GluR1 HET mice have not previously been assessed for cognitive function. Impaired one-trial fear conditioning in GluR1 HET is, however, reminiscent of deficits in one-trial context fear conditioning in mice lacking NMDA-NR1 receptors in the CA3 region of the hippocampus (Cravens et al., 2006; Nakazawa et al., 2003). Interestingly, NR1-CA3 K0 mice also exhibit impairments in context fear conditioning when restricted context-exposure forces the rapid formation of a mnemonic representation of the context (Cravens et al., 2006). A major question for future studies therefore will be whether GluR1 HET are similarly impaired on other tasks requiring rapid and memory formation.

\section{CONCLUSION}

In summary, the present study confirms and extends evidence of impairments in the formation of associative fear memories following disruption of GluR1-containing AMPA receptors. Complete loss of GluR1 led to a severe deficit in tone and context forms of delay and trace fear conditioning. GluR1 haploinsufficiency produced a selective deficit on one-trial delay conditioning. These data add support to the broader hypothesis that the molecular mechanisms subserving learning and memory involve GluR1-containing AMPA receptors (Collingridge et al., 2004; Malinow and Malenka, 2002). A better understanding of the role of GluR1 in the formation of emotional memory could ultimately have important implications for understanding the pathophysiology and therapeutic alleviation of neuropsychiatric disorder states ranging from affective illness to addiction.

\section{CONFLICT OF INTEREST STATEMENT}

The authors declare that the research was conducted in the absence of any commercial or financial relationships that could be construed as a potential conflict of interest.

\section{ACKNOWLEDGMENTS}

This work was supported by the National Institute on Alcohol Abuse and Alcoholism Intramural Research Program.

\section{REFERENCES}

Balleine, B. W., and Dickinson, A. (1998). Goal-directed instrumental action: contingency and incentive learning and their cortical substrates. Neuropharmacology 37, 407419.

Bannerman, D. M., Deacon, R. M., Brady, S., Bruce, A., Sprengel, R., Seeburg, P. H., and Rawlins, J. N. (2004). A comparison of GluR-A-deficient and wild-type mice on a test battery assessing sensorimotor, affective, and cognitive behaviors. Behav. Neurosci. $118,643-647$

Bannerman, D. M., Rawlins, J. N., and Good, M. A. (2006). The drugs don't work-or do they? Pharmacological and transgenic studies of the contribution of NMDA and GluRA-containing AMPA receptors to hippocampal-dependent memory. Psychopharmacology (Berl) 188, 552-566.

Bast, T., da Silva, B. M., and Morris, R. G. M. (2005). Distinct Contributions of Hippocampal NMDA and AMPA Receptors to Encoding and Retrieval of One-Trial Place Memory. J. Neurosci. 25, 5845-5856.

Bonini, J. S., Rodrigues, L., Kerr, D. S., Bevilaqua, L. R., Cammarota, M., and Izquierdo, I. (2003). AMPA/kainate and group-I metabotropic receptor antagonists infused into different brain areas impair memory formation of inhibitory avoidance in rats. Behav. Pharmacol. 14, 161-166.

Boyce-Rustay, J. M., and Holmes, A. (2006). Genetic inactivation of the NMDA receptor NR2A subunit has anxiolytic- and antidepressant-like effects in mice. Neuropsychopharmacology 31, 2405-2414.

Bozon, B., Davis, S., and Laroche, S. (2003). A requirement for the immediate early gene zif268 in reconsolidation of recognition memory after retrieval. Neuron 40, 695-701.

Collingridge, G. L., Isaac, J. T., and Wang, Y. T. (2004). Receptor trafficking and synaptic plasticity. Nat. Rev. Neurosci. 5, 952-962.

Cravens, C. J., Vargas-Pinto, N., Christian, K. M., and Nakazawa, K. (2006). CA3 NMDA receptors are crucial for rapid and automatic representation of context memory. Eur. J. Neurosci. 24, 1771-1780.

Day, M., Langston, R., and Morris, R. G. (2003). Glutamate-receptor-mediated encoding and retrieval of paired-associate learning. Nature 424, 205-209.

De Leonibus, E., Costantini, V. J., Castellano, C., Ferretti, V., Oliverio, A., and Mele, A. (2003). Distinct roles of the different ionotropic glutamate receptors within the nucleus accumbens in passive-avoidance learning and memory in mice. Eur. J. Neurosci. 18, 2365-2373.

Dere, E., Huston, J. P., and De Souza Silva, M. A. (2007). The pharmacology, neuroanatomy and neurogenetics of one-trial object recognition in rodents. Neurosci. Biobehav. Rev. 31, 673-704.

Everitt, B., Cardinal, R., Hall, J., Parkinson, J., and Robbins, T. (2000). Differential involvement of amygdala subsystems in appetitive conditioning and drug addiction. In The amygdala , Vol. 2, J. Aggleton, ed. (New York, Oxford University Press), pp. 353-390.

Fanselow, M. S., and LeDoux, J. E. (1999). Why we think plasticity underlying Pavlovian fear conditioning occurs in the basolateral amygdala. Neuron 23, 229-232.

Fanselow, M. S., and Poulos, A. M. (2005). The neuroscience of mammalian associative learning. Annu. Rev. Psychol. 56, 207-234.

Hartmann, B., Ahmadi, S., Heppenstall, P. A., Lewin, G. R., Schott, C., Borchardt, T., Seeburg, P. H., Zeilhofer, H. U., Sprengel, R., and Kuner, R. (2004). The AMPA receptor subunits GluR-A and GluR-B reciprocally modulate spinal synaptic plasticity and inflammatory pain. Neuron 44, 637-650.

Hatfield, T., Han, J. S., Conley, M., Gallagher, M., and Holland, P. (1996). Neurotoxic lesions of basolateral, but not central, amygdala interfere with Pavlovian secondorder conditioning and reinforcer devaluation effects. J. Neurosci. 16, 5256-5265.

Hefner, K., and Holmes, A. (2007). An investigation of the behavioral actions of ethanol across adolescence in mice. Psychopharmacology (Berl) 191, 311-322.

Hitchcott, P. K., and Phillips, G. D. (1997). Amygdala and hippocampus control dissociable aspects of drug-associated conditioned rewards. Psychopharmacology (Berl) 131, 187-195.

Hoffman, D. A., Sprengel, R., and Sakmann, B. (2002). Molecular dissection of hippocampal theta-burst pairing potentiation. Proc. Natl. Acad. Sci. USA 99, 7740-7745.

Hu, H., Real, E., Takamiya, K., Kang, M. G., Ledoux, J., Huganir, R. L., and Malinow, R. (2007). Emotion enhances learning via norepinephrine regulation of AMPA-receptor trafficking. Cell 131, 160-173.

Huerta, P. T., Sun, L. D., Wilson, M. A., and Tonegawa, S. (2000). Formation of temporal memory requires NMDA receptors within CA1 pyramidal neurons. Neuron 25, 473-480.

Humeau, Y., Reisel, D., Johnson, A. W., Borchardt, T., Jensen, V., Gebhardt, C., Bosch, V., Gass, P., Bannerman, D. M., Good, M. A., Hvalby, O., Sprengel, R., and Lüthi, A. (2007). A pathway-specific function for different AMPA receptor subunits in amygdala LTP and fear conditioning. J. Neurosci. 27, 10947-10956.

Johnson, A. W., Bannerman, D. M., Rawlins, N. P., Sprengel, R., and Good, M. A. (2005), Impaired outcome-specific devaluation of instrumental responding in mice with a targeted deletion of the AMPA receptor glutamate receptor 1 subunit. J. Neurosci. 25, 2359-2365.

Jones, M. W., Errington, M. L., French, P. J., Fine, A., Bliss, T. V., Garel, S., Charnay, P., Bozon, B., Laroche, S., and Davis, S. (2001). A requirement for the immediate early gene Zif268 in the expression of late LTP and long-term memories. Nat. Neurosci. 4 , 289-296.

Kim, J. J., and Fanselow, M. S. (1992). Modality-specific retrograde amnesia of fear. Science 256, 675-677.

Kim, J. J., Clark, R. E., and Thompson, R. F. (1995). Hippocampectomy impairs the memory of recently, but not remotely, acquired trace eyeblink conditioned responses. Behav. Neurosci. 109, 195-203.

Kogan, J. H., Frankland, P. W., Blendy, J. A., Coblentz, J., Marowitz, Z., Schutz, G., and Silva, A. J. (1997). Spaced training induces normal long-term memory in CREB mutant mice. Curr. Biol. 7, 1-11.

LeDoux, J. E. (2000). Emotion circuits in the brain. Annu. Rev. Neurosci. 23, 155-184. Lledo, P. M., Zhang, X., Sudhof, T. C., Malenka, R. C., and Nicoll, R. A. (1998). Postsynaptic membrane fusion and long-term potentiation. Science 279, 399-403.

Mack, V., Burnashev, N., Kaiser, K. M., Rozov, A., Jensen, V., Hvalby, O., Seeburg, P. H., Sakmann, B., and Sprengel, R. (2001). Conditional restoration of hippocampal synaptic potentiation in Glur-A-deficient mice. Science 292, 2501-2504.

Malinow, R., and Malenka, R. C. (2002). AMPA receptor trafficking and synaptic plasticity. Annu. Rev. Neurosci. 25, 103-126.

Maren, S., and Quirk, G. J. (2004). Neuronal signalling of fear memory. Nat. Rev. Neurosci. 5, 844-852.

McDonald, A. J. (1996). Localization of AMPA glutamate receptor subunits in subpopulations of non-pyramidal neurons in the rat basolateral amygdala. Neurosci. Lett. 208, 175-178.

Mead, A. N., and Stephens, D. N. (2003). Selective disruption of stimulus-reward learning in glutamate receptor gria1 knock-out mice. J. Neurosci. 23, 10411048.

Mead, A. N., Brown, G., Le Merrer, J., and Stephens, D. N. (2005). Effects of deletion of gria1 or gria2 genes encoding glutamatergic AMPA-receptor subunits on place preference conditioning in mice. Psychopharmacology (Berl) 179, 164171.

Misane, I., Tovote, P., Meyer, M., Spiess, J., Ogren, S. 0., and Stiedl, 0. (2005). Timedependent involvement of the dorsal hippocampus in trace fear conditioning in mice. Hippocampus 15, 418-426.

Nakazawa, K., Sun, L. D., Quirk, M. C., Rondi-Reig, L., Wilson, M. A., and Tonegawa, S. (2003). Hippocampal CA3 NMDA receptors are crucial for memory acquisition of one-time experience. Neuron 38, 305-315.

Reisel, D., Bannerman, D. M., Schmitt, W. B., Deacon, R. M., Flint, J., Borchardt, T., Seeburg, P. H., and Rawlins, J. N. (2002). Spatial memory dissociations in mice lacking GluR1. Nat. Neurosci. 5, 868-873.

Rumpel, S., LeDoux, J., Zador, A., and Malinow, R. (2005). Postsynaptic receptor trafficking underlying a form of associative learning. Science $308,83-88$. 
Schmitt, W. B., Deacon, R. M., Seeburg, P. H., Rawlins, J. N., and Bannerman, D. M. (2003). A within-subjects, within-task demonstration of intact spatial reference memory and impaired spatial working memory in glutamate receptor-A-deficient mice. J. Neurosci. 23, 3953-3959.

Schmitt, W. B., Arianpour, R., Deacon, R. M., Seeburg, P. H., Sprengel, R., Rawlins, J. N. and Bannerman, D. M. (2004a). The role of hippocampal glutamate receptorA-dependent synaptic plasticity in conditional learning: the importance of spatiotemporal discontiguity. J. Neurosci. 24, 7277-7282.

Schmitt, W. B., Deacon, R. M., Reisel, D., Sprengel, R., Seeburg, P. H., Rawlins, J. N., and Bannerman, D. M. (2004b). Spatial reference memory in GluR-A-deficient mice using a novel hippocampal-dependent paddling pool escape task. Hippocampus 14, $216-$ 223.

Schmitt, W. B., Sprengel, R., Mack, V., Draft, R. W., Seeburg, P. H., Deacon, R. M., Rawlins, J. N., and Bannerman, D. M. (2005). Restoration of spatial working memory by genetic rescue of GluR-A-deficient mice. Nat. Neurosci. 8, 270272

Shi, S., Hayashi, Y., Esteban, J. A., and Malinow, R. (2001). Subunit-specific rules governing AMPA receptor trafficking to synapses in hippocampal pyramidal neurons. Cell 105, 331-343.
Sprengel, R. (2006). Role of AMPA receptors in synaptic plasticity. Cell Tissue Res. 326 $447-455$

Stephens, D. N., and Mead, A. N. (2003). What role do GluR1 subunits play in drug abuse? Trends Neurosci. 26, 181-182; Author reply 182-183.

Wanisch, K., Tang, J., Mederer, A., and Wotjak, C. T. (2005). Trace fear conditioning depends on NMDA receptor activation and protein synthesis within the dorsa hippocampus of mice. Behav. Brain Res. 157, 63-69.

Weidholz, L. M., Owen, A. M., Horton, R. E., Feyder, M., Karlsson, R. M., Hefner, K, Sprengel, R., Ceikel, T., Daws, L. C., and Holmes, A. (2007). Mice lacking the AMPA GluR1 receptor exhibit striatal hyperdopaminergia and 'schizophrenia-related' behaviors. Mol. Psychiatry D0I:10.1038/sj.mp.4002056.

Yeh, S. H., Mao, S. C., Lin, H. C., and Gean, P. W. (2006). Synaptic expression of glutamate receptor after encoding of fear memory in the rat amygdala. Mol. Pharmacol. 69, 299-308.

Zamanillo, D., Sprengel, R., Hvalby, O., Jensen, V., Burnashev, N., Rozov, A., Kaiser, K. M., Koster, H. J., Borchardt, T., Worley, P., Lubke, J., Frotscher, M., Kelly, P. H. Sommer, B., Andersen, P., Seeburg, P. H., and Sakmann, B. (1999). Importance of AMPA receptors for hippocampal synaptic plasticity but not for spatial learning. Science 284, 1805-1811. 